\title{
Teores de clorofilas do milho submetido a fertirrigação com água residuária de suinocultura e piscicultura
}

\author{
Chlorophyll contents of corn submitted to fertigation with swine and fish wastewater \\ Contenido de clorofila del maíz sometido a fertirrigación con aguas residuales porcinas y peces
}

Recebido: 18/05/2021 | Revisado: 27/05/2021 | Aceito: 27/05/2021 | Publicado: 12/06/2021

Daniely Karen Matias Alves

ORCID: https://orcid.org/0000-0001-7427-7545

Instituto Federal de Educação, Ciência e Tecnologia Goiano, Brasil

E-mail: daniely_karen@hotmail.com

Marconi Batista Teixeira

ORCID: https://orcid.org/0000-0002-0152-256X

Instituto Federal de Educação, Ciência e Tecnologia Goiano, Brasil

E-mail: marconibt@gmail.com

Fernando Rodrigues Cabral Filho

ORCID: https://orcid.org/0000-0002-5090-5946

Instituto Federal de Educação, Ciência e Tecnologia Goiano, Brasil

E-mail: fernandorcfilho@ hotmail.com

Fernando Nobre Cunha

ORCID: https://orcid.org/0000-0001-8489-7625

Instituto Federal de Educação, Ciência e Tecnologia Goiano, Brasil

E-mail: fernandonobrecunha@hotmail.com

Frederico Antonio Loureiro Soares

ORCID: https://orcid.org/0000-0002-4152-5087

Instituto Federal de Educação, Ciência e Tecnologia Goiano, Brasil

E-mail: frederico.soares@ifgoiano.edu.br

Gustavo da Silva Vieira

ORCID: https://orcid.org/0000-0002-0877-3900

Instituto Federal de Educação, Ciência e Tecnologia Goiano, Brasil

E-mail: gustavovieira620@gmail.com

Maykelle Vieira Mendes Gonçalves

ORCID: https://orcid.org/0000-0003-0640-6485

Instituto Federal de Educação, Ciência e Tecnologia Goiano, Brasil

E-mail: maykellevmg@gmail.com

Leonardo Nazário Silva dos Santos

ORCID: http://orcid.org/0000-0002-3951-3888

Instituto Federal de Educação, Ciência e Tecnologia Goiano, Brasil

E-mail: leonardo.santos@ifgoiano.edu.br

\begin{abstract}
Resumo
A fertirrigação com águas residuárias é uma excelente alternativa do ponto de vista agronômico e ambiental, para o fornecimento de nitrogênio para a cultura do milho. O objetivo deste estudo foi avaliar o efeito comparativo entre a fertirrigação com água residuária de piscicultura e de suinocultura em diferentes diluições no índice de clorofila das folhas do milho. O experimento foi conduzido em vasos plásticos, dispostos a céu aberto, na estação experimental do Instituto Federal Goiano - Campus Rio Verde - GO. O solo utilizado foi classificado como Latossolo Vermelho distroférrico, fase Cerrado, de textura argilosa. O delineamento experimental utilizado foi em blocos ao acaso, analisado em esquema de parcelas subdivididas $2 \times 4$, com três repetições. Os tratamentos consistiram em duas fontes de água residuária (piscicultura e suinocultura) diluídas em quatro proporções de água de abastecimento, sendo: dose recomendada de água residuária $+0,25,50,75 \%$ de seu volume em água de abastecimento. Os teores de clorofilas foram avaliados aos 30, 60 e 90 dias após a semeadura, quantificando-se: clorofila $a$, clorofila $b$, clorofila total e o índice SPAD. A fonte água residuária de suinocultura proporciona o maior teor de clorofila $a$, clorofila $b$, clorofila total e leitura SPAD no final do ciclo do milho.
\end{abstract}

Palavras-chave: Zea mays L.; Adubação nitrogenada; Efluentes; Nitrogênio. 


\begin{abstract}
Fertigation with wastewater is an excellent alternative from an agronomic and environmental point of view, for the supply of nitrogen for the cultivation of corn. The aim of this study was to evaluate the comparative effect between fertigation with fish and swine wastewater at different dilutions in the chlorophyll index of corn leaves. The experiment was conducted in plastic vases, arranged in the open, at the experimental station of the Instituto Federal Goiano - Campus Rio Verde - GO. The soil used was classified as dystrophic Red Latosol, Cerrado phase, with a clay texture. The experimental design used was in randomized blocks, analyzed in a $2 \times 4$ subdivided plot scheme, with three replications. The treatments consisted of two sources of waste water (fish and pig farming) diluted in four proportions of water supply, being: recommended dose of waste water $+0,25,50,75 \%$ of its volume in water supply. Chlorophyll contents were evaluated at 30, 60 and 90 days after sowing, quantifying: chlorophyll a, chlorophyll b, total chlorophyll and the SPAD index. The source of swine wastewater provides the highest content of chlorophyll a, chlorophyll $b$, total chlorophyll and SPAD reading at the end of the corn cycle.
\end{abstract}

Keywords: Zea mays L.; Nitrogen fertilization; Effluents; Nitrogen.

\title{
Resumen
}

La fertilización con aguas residuales es una excelente alternativa desde el punto de vista agronómico y ambiental, para el aporte de nitrógeno para el cultivo de maíz. El objetivo de este estudio fue evaluar el efecto comparativo entre fertirrigación con peces y aguas residuales porcinas a diferentes diluciones en el índice de clorofila de hojas de maíz. El experimento se realizó en jarrones de plástico, dispuestos al aire libre, en la estación experimental del Instituto Federal Goiano - Campus Rio Verde - GO. El suelo utilizado fue clasificado como Latosol Rojo distrófico, fase Cerrado, con textura arcillosa. El diseño experimental utilizado fue en bloques al azar, analizados en un esquema de parcelas subdivididas de $2 \times 4$, con tres repeticiones. Los tratamientos consistieron en dos fuentes de aguas residuales (peces y porcinos) diluidas en cuatro proporciones de suministro de agua, a saber: dosis recomendada de agua residual $+0,25,50,75 \%$ de su volumen en el suministro de agua. Se evaluó el contenido de clorofila a los 30, 60 y 90 días después de la siembra, cuantificando: clorofila a, clorofila b, clorofila total e índice SPAD. La fuente de aguas residuales porcinas proporciona el mayor contenido de clorofila a, clorofila $b$, clorofila total y lectura de SPAD al final del ciclo del maíz.

Palabras clave: Zea mays L.; Fertilización con nitrógeno; Efluentes; Nitrógeno.

\section{Introdução}

O milho está presente em todos os estados brasileiros, todavia com níveis tecnológicos bem distintos, de acordo com cada região, cujo estado de Goiás é o quarto maior produtor de milho do Brasil, participando com quase $10 \%$ de toda produção nacional (Neto, 2019). Rio Verde, situado no sudoeste goiano, representa um dos seis principais municípios produtores de milho de Goiás, com produção de 1.328,100 mil toneladas, que correspondem a 14\% da produção total do Estado (IBGE, 2018), de forma que existe uma tendência natural de crescimento na demanda e produtividade dessa cultura.

Aliado ao acréscimo de produtividade, está o aumento do requerimento nutricional, cujo nitrogênio (N) é o nutriente mais absorvido e extraído pela cultura do milho (Moreira et al., 2019). Dados de extração total de N situam-se entre 216 e 362 $\mathrm{kg} \mathrm{ha}^{-1}$ para produtividades entre 10.000 a $14.000 \mathrm{~kg} \mathrm{ha}^{-1}$ de grãos, conforme relatado por Coelho e França (1995) e Von Pinho et al. (2009). Este nutriente desempenha papel fundamental como constituinte essencial dos aminoácidos, principais integrantes de proteínas no milho (Gonçalves et al., 2016), portanto, é o nutriente que mais influência na produção de clorofila, acúmulo de matéria seca e a produtividade de grãos (Silva et al., 2013) e o que mais onera o custo de produção (Melo et al., 2011).

Dentre os fertilizantes nitrogenados mais utilizados no Brasil, a ureia é a mais empregada para adubação em culturas, principalmente em gramíneas, devido à alta concentração de $\mathrm{N}$ e ao menor preço por unidade de nutriente aplicado. O aumento dos custos de adubos nitrogenados e os cuidados com a preservação ambiental, tem conduzido a uma situação de manejo e utilização mais eficiente do nitrogênio (Lopes e Lima 2011). Diante dessa situação, torna-se necessária a busca por fontes alternativas de adubação que permitam o cultivo do milho com menor agressão ao meio ambiente agrícola e maior eficiência econômica, sem causar prejuízos na produtividade de grãos.

As águas residuárias provenientes das atividades de suinocultura e piscicultura possibilitam o aporte e reciclagem de nutrientes para as plantas, atuando como complemento no processo de adubação (Bastos, 2016, Nascimento et al., 2016). Desta forma, viabiliza-se a utilização desses efluentes na agricultura irrigada, conforme já relatado por Cassol et al. (2012), Moraes et 
al. (2014) e Neto et al. (2016), ao constatar efeitos positivos da aplicação de água residuária na produtividade de grãos de milho. A prática de fertirrigação de culturas anuais e perenes com esses efluentes é considerada uma fonte de adubação orgânica importante, que requer monitoramento no perfil do solo, a fim de garantir sustentabilidade agrícola e ambiental (Silva et al., 2018).

Com base no exposto acima, o objetivo deste estudo foi avaliar o efeito comparativo entre a fertirrigação via gotejamento com água residuária de piscicultura e de suinocultura em diferentes diluições no índice de clorofila das folhas do milho, cultivado em Latossolo Vermelho no Cerrado.

\section{Metodologia}

A pesquisa desenvolvida neste estudo foi uma pesquisa em campo, de natureza quantitativa e qualitativa (Pereira et al. 2018), que descreve a influência dos fatores águas residuárias e diluições na cultura do milho, cultivada no Sudoeste Goiano. O experimento foi conduzido em vasos plásticos, dispostos a céu aberto, no período de junho a outubro de 2019, na estação experimental do Instituto Federal Goiano - Campus Rio Verde - GO. A área encontra-se a $720 \mathrm{~m}$ de altitude e nas coordenadas geográficas de $17^{\circ} 48^{\prime 2} 28^{\prime \prime} \mathrm{S}$ e $50^{\circ} 53^{\prime} 57^{\prime \prime}$ O. O clima da região é classificado conforme Köppen e Geiger (1928), como Aw (tropical), com chuva nos meses de outubro a maio, e com seca nos meses de junho a setembro. A temperatura média anual varia de 20 a $35^{\circ} \mathrm{C}$ e as precipitações variam de 1.500 a $1.800 \mathrm{~mm}$ anuais e o relevo é suave ondulado $(6 \%$ de declividade).

O solo utilizado para o preenchimento dos vasos foi classificado como Latossolo Vermelho distroférrico (LVdf), fase Cerrado, de textura argilosa (Santos et al., 2018), coletado na camada de 0,0-0,20 m de profundidade em uma área de Cerrado nativo pertencente ao IF Goiano - Campus Rio Verde.

O delineamento experimental utilizado foi em blocos ao acaso, analisado em esquema de parcelas subdivididas $2 \times 4$, com três repetições. Os tratamentos consistiram em duas fontes de água residuária (piscicultura e suinocultura) diluídas em quatro proporções de água de abastecimento, sendo: dose recomendada de água residuária (Matos e Matos, 2017) + 0, 25, 50, $75 \%$ de seu volume em água de abastecimento, totalizando 24 parcelas experimentais. Cada parcela foi constituída por quatro vasos com uma planta de milho, totalizando 96 unidades experimentais.

A dose de água residuária aplicada na fertirrigação do milho foi calculada de acordo com Matos e Matos (2017), levando em consideração a demanda de nitrogênio $(\mathrm{N})$ pela planta, a quantidade de $\mathrm{N}$ presente no solo adotado e a concentração de $\mathrm{N}$ fornecida pelas águas residuárias, utilizando-se a equação 1 .

$\mathrm{DAR}=\frac{1000 \times\left[\operatorname{Nabs}-\left(\operatorname{Tm} 1 \times \mathrm{M} . \mathrm{O} \times \rho \mathrm{s} \times \mathrm{P} \times 10^{7} \times 0,05 \times \frac{\mathrm{n}}{12}\right)\right]}{\left[\operatorname{Tm} 2 \times \frac{\mathrm{n}}{12} \times \operatorname{Norg}+(\text { Namon }+ \text { Nnitrato }) \times \mathrm{PR}\right]}$

onde: DAR: dose de água residuária a ser aplicada $\left(\mathrm{m}^{3} \mathrm{ha}^{-1}\right)$, Nabs: absorção de $\mathrm{N}$ para obtenção da produtividade desejada $(\mathrm{kg}$ ha $^{-1}$ ) (Sousa, Lobato, 2004), Tm1: taxa anual de mineralização da matéria orgânica já existente no solo (adimensional), M.O: conteúdo de matéria orgânica do solo $\left(\mathrm{kg} \mathrm{kg}^{-1}\right), \rho \mathrm{s}=$ massa específica do solo $\left(\mathrm{t} \mathrm{m}^{-3}\right)$, P: profundidade do solo considerada $(\mathrm{m})$, n: duração do ciclo da cultura, Tm2: taxa de mineralização do nitrogênio orgânico (adimensional), Norg: nitrogênio orgânico (mg L $\left.{ }^{-1}\right)$, Namon: nitrogênio amoniacal $\left(\mathrm{mg} \mathrm{L}^{-1}\right)$, Nnitrato: nitrogênio nítrico $\left(\mathrm{mg} \mathrm{L}^{-1}\right)$ e PR: recuperação do $\mathrm{N}$ mineral pela cultura (adimensional). 
Para atender a demanda de nitrogênio pelo milho, visando uma produtividade de $10 \mathrm{t} \mathrm{ha}^{-1}$, conforme recomendação de Sousa e Lobato (2004), foram necessários 17,09 L de água residuária de piscicultura planta ${ }^{-1}$ e 2,08 L de água residuária de suinocultura planta ${ }^{-1}$, parcelados em dois momentos de fertirrigação.

A aplicação de nitrogênio via fertirrigação com água residuária de piscicultura e suinocultura foi realizada em cobertura do milho, nos estádios fenológicos V4 e V6, conforme a recomendação de Sousa e Lobato (2004) (100 kg ha ${ }^{-1}$ de nitrogênio), seguindo a dose recomendada para cada fonte de água residuária conforme o ítem 3.2.4, diluídas conforme os tratamentos descritos.

Os teores de clorofilas foram avaliados aos 30, 60 e 90 dias após a semeadura (DAS), quantificando-se: Clorofila $a$ (CLRa), Clorofila $b$ (CLR $b$ ) e a Clorofila total (CLR $t)$ utilizando-se o aparelho Falker ClorofiLOG ${ }^{\circledR} 1030$ (Falker, 2008). O Índice SPAD (SPAD) foi obtido com auxílio do aparelho Minolta SPAD ${ }^{\circledR} 502$ (Minolta, 1989).

Os dados das variáveis de clorofilas e matéria seca obtidos em cada fase de desenvolvimento e das variáveis produtivas foram submetidos à análise da variância, aplicando-se o teste $\mathrm{F}$ ao nível de $5 \%$ de probabilidade e, em casos de significância, foi realizada a análise de regressão polinomial linear e quadrática para os níveis diluições (D). Para o fator fontes (F) de água residuária, as médias foram comparadas entre si pelo teste Tukey a 5\% de probabilidade, utilizando o programa estatístico $\operatorname{SISVAR}^{\circledR}$ (Ferreira, 2011).

\section{Resultados e Discussão}

Efeito da interação Diluição x Fonte (D x F) foi observado para o teor de Clorofila $a$ (CLRa) aos 30 dias após a semeadura (DAS), Clorofila $b$ (CLR $b$ ) aos 30, 60 e 90 DAS, Clorofila Total (CLR $t$ ) e índice SPAD aos 30 DAS. Ocorreu efeito significativo do fator isolado fontes (F) de água residuária para CLR $a$ e CLR $t$ aos 90 DAS e índice SPAD aos 60 e 90 DAS.

Nota-se uma diferença no comportamento da CLRa aos 30 DAS, quando se avalia as diluições em cada fonte de água residuária. Para a fonte água residuária de piscicultura (ARP), a CLRa adequou-se a uma equação polinomial do segundo grau, cuja diluição de 29,5\% proporcionou a maior quantidade de CLRa, estimada em 29,20 índices de clorofila Falker (ICF). Já para a fonte água residuária de suinocultura (ARS), a diluição de 37\% promoveu a menor quantidade de CLRa (25,3 ICF), enquanto a diluição de 75\% proporcionou o maior valor de CLR $a$ (31,39 ICF) (Figura 1A). Os maiores teores de clorofila $a$ deste estudo são superiores aos obtidos por Martins et al. (2018), que aos 30 DAS encontraram esse pigmento estimado em 22,86 ICF nas folhas de milho.

Ocorreu diferença significativa quando comparada as fontes utilizadas apenas nas D de 0\% e 75\% (Figura 1B), em que a fonte ARS proporcionou um aumento de $17,11 \%$ e 36,96\%, respectivamente, na quantidade de CLRa quando contrastada com a fonte ARP. Segundo Piekielek et al. (1995), o teor de clorofila na folha é utilizado para predizer o nível nutricional de nitrogênio nas plantas, pelo fato de a quantidade desse pigmento correlacionar-se positivamente com o teor de $\mathrm{N}$.

Aos 90 DAS, as fontes tiveram influência na quantidade de Clorofilas $a$ (CRLa), em que a fonte ARS apresentou um valor de 34,45 ICF, sendo, 10,56\% superior ao observado na fonte ARP (Figura 1C). 
Figura 1. Desdobramento da interação diluição $x$ fontes de água residuária (piscicultura - ARP e suinocultura - ARS) para a clorofila $a(\mathrm{CLR} a$ ) no milho aos 30 dias após a semeadura (DAS) (A e B) e, CLRa no milho em função das fontes de água residuária aos 90 DAS (C).

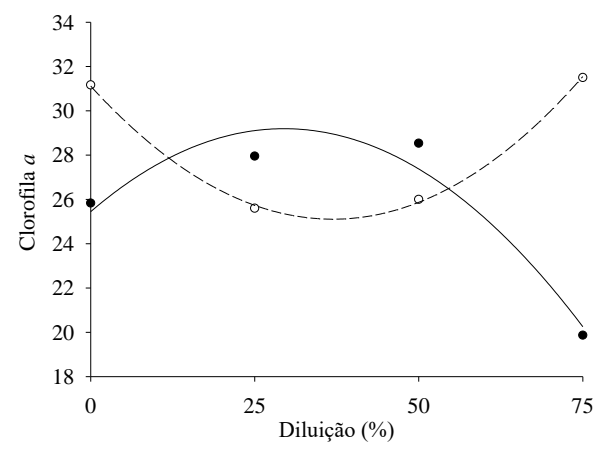

- $\quad \mathrm{ARP}-\mathrm{CLR} a 30 \mathrm{DAS}=25,448+0,2542 * \mathrm{X}-0,0043 * * \mathrm{X}^{2}-\mathrm{R}^{2}=0,9367$ - ARS - CLR $a 30$ DAS $=31,123-0,3264 * * X+0,0044 * * X^{2}-R^{2}=0,9988$
B

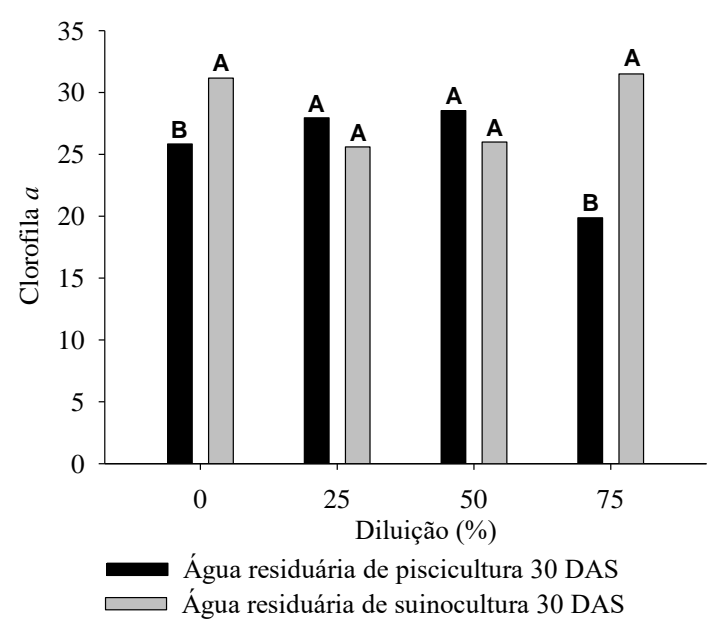

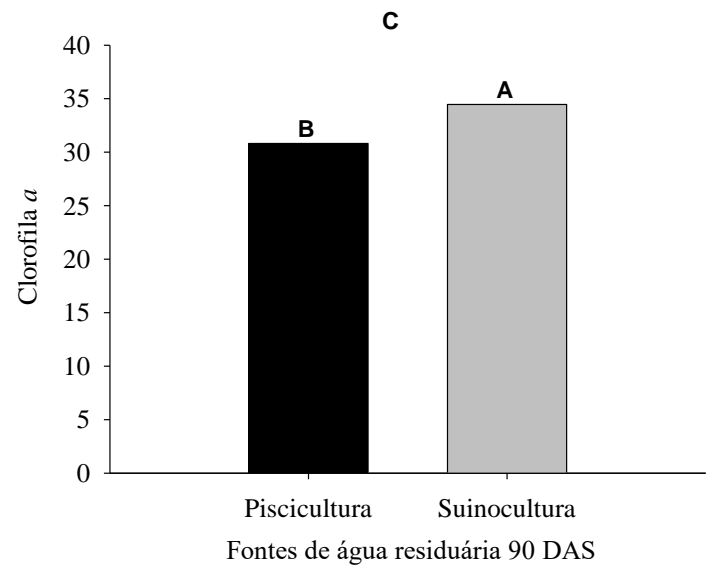

Fonte: Autores (2021).

Com relação à CLR $b$ aos 30 DAS, as diluições de 34\% e 50\% estimaram o maior e o menor valor para as fontes ARP e ARS, iguais a 6,33 e 4,59 ICF, respectivamente (Figura 2A). Conforme observado na Figura 2C, os dados de CLR $b$ aos 60 DAS, para a fonte ARS não se adequaram aos modelos de equações testadas. Para a fonte ARP, a CLR $b$ adequou-se a uma equação polinomial do segundo grau, cuja diluição de 43\% estimou a maior quantidade de CLR $b$ (11,45 ICF). Aos 90 DAS, a maior quantidade de CLR $b$ (17,68 ICF) foi estimada na diluição de 35\% (Figura 2E) para a fonte ARS, um teor semelhante ao encontrado por Cabral Filho (2019), também nesta mesma fase fenológica do do milho, cujos valores máximos obtidos desse pigmento foram próximos a 18,00 ICF.

Ocorreu diferença entre as fontes utilizadas apenas na D de 0\% e 75\% aos 30 e 60 DAS (Figura 2B e Figura 2D), em que a fonte ARS proporcionou um aumento de CLR $b$ na ordem de 49,46\% e 40,74\% aos 30 e 60 DAS, respectivamente, na diluição de $0 \%$ e, 38,92 e 21,13\% aos 30 e 60 DAS, respectivamente, na diluição de 75\%, quando contrastada com a fonte ARP. Contudo, aos 90 DAS, houve diferença significativa entre as fontes nas diluições de $25 \%$, 50\% e $75 \%$, cuja fonte ARS apresentou, respectivamente, uma quantidade 46,38, 41,29 e 28,64\% superior de CRL $b$ em comparação à fonte ARP (Figura $2 \mathrm{~F})$. 
Figura 2. Desdobramento da interação diluição $x$ fontes de água residuária (piscicultura - ARP e suinocultura - ARS) para a clorofila $b$ (CLR $b)$ no milho aos 30 (A e B), 60 (C e D) e 90 dias após a semeadura (DAS) (E e F).

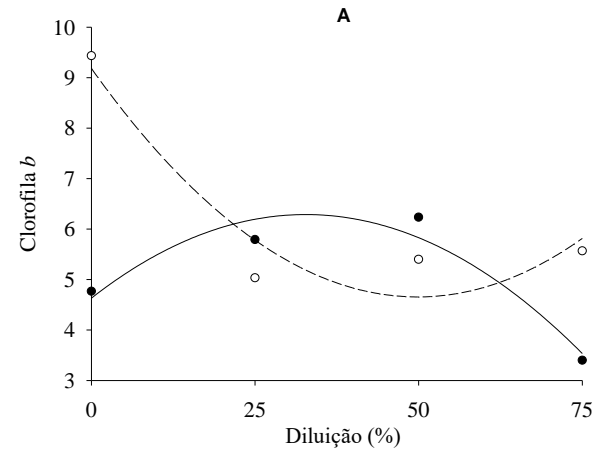

ARP - CLR $b 30$ DAS $=4,6318+0,1011 * * X-0,0015 * * X^{2}-R^{2}=0,9235$ ARS - CLR $b 30$ DAS $=9,185-0,1819 * * X+0,0018 * * X^{2}-R^{2}=0,9033$

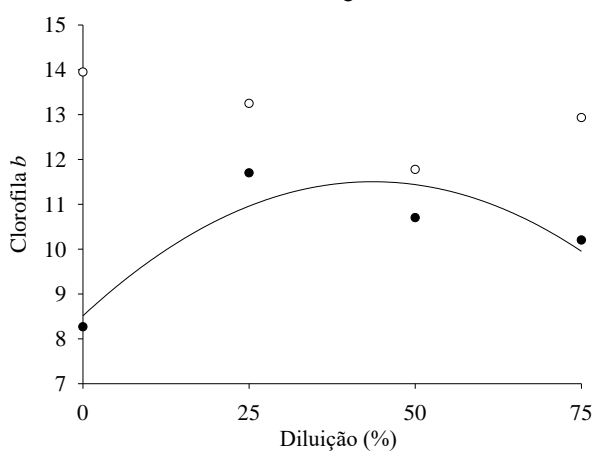

- $\quad \mathrm{ARP}-\mathrm{CLR} b 60$ DAS $=8,5133+0,1372 * * \mathrm{X}-0,0016 * * \mathrm{X}^{2}-\mathrm{R}^{2}=0,8049$ - ARS - CLR $b 60$ DAS

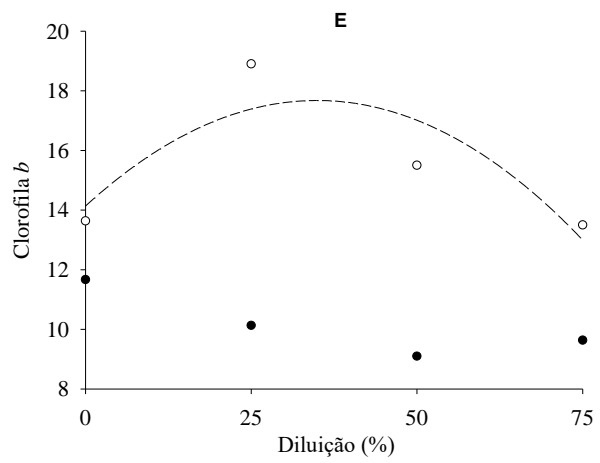

- $\quad$ ARP - CLR $b 90$ DAS

- ARS - CLR $b$ 90 DAS $=14,137+0,2028 * * X-0,0029 * * X^{2}-R^{2}=0,7332$

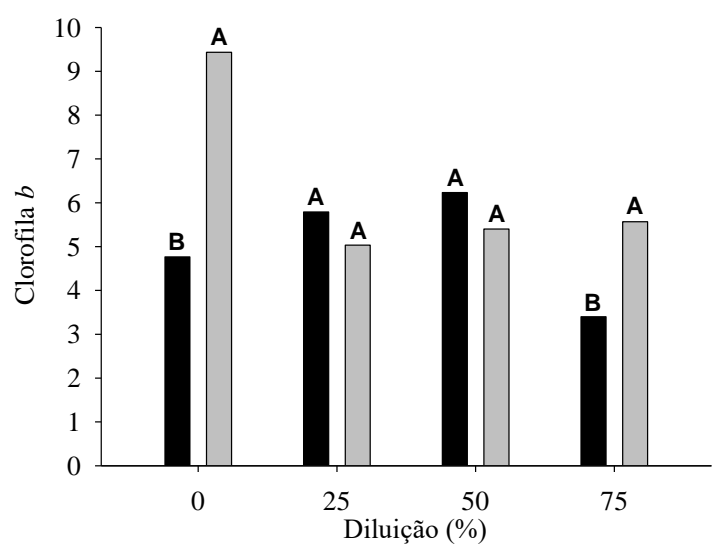

Água residuária de piscicultura 30 DAS Água residuária de suinocultura 30 DAS

D

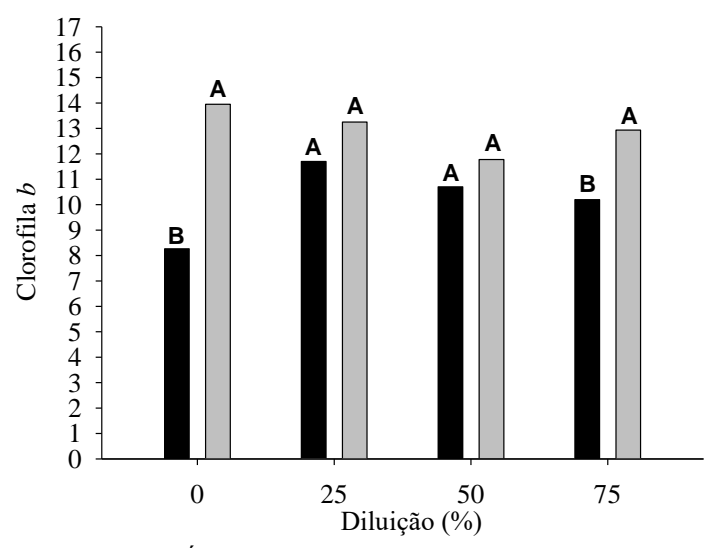

Água residuária de piscicultura 60 DAS $\square$ Água residuária de suinocultura 60 DAS

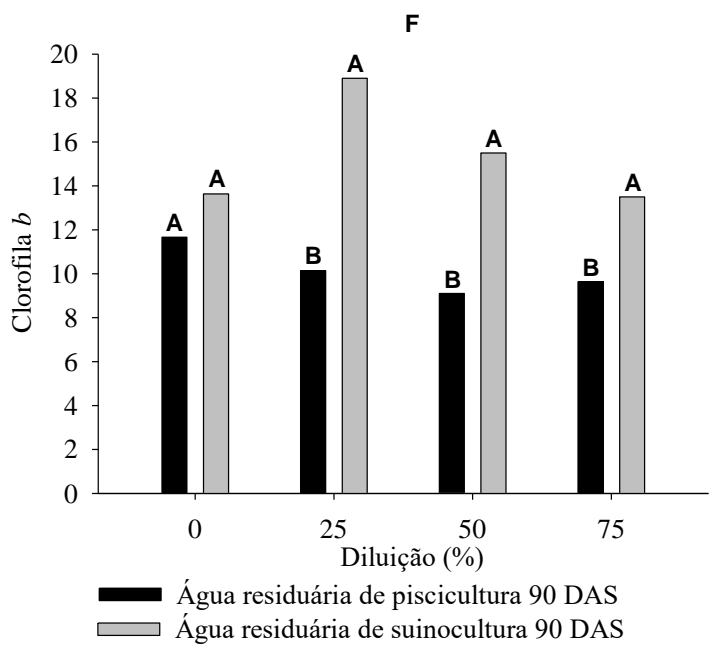

Fonte: Autores (2021). 
Com as diluições de 30 e 50\% aos 30 DAS, foram estimados o maior e o menor valor de CLRt para as fontes ARP e ARS, iguais a 35,52 e 29,52 ICF, respectivamente (Figura 3A). Ocorreu diferença estatística entre as fontes utilizadas na D de $0 \%$ e $75 \%$, em que a fonte ARS proporcionou um aumento de 26,63 e 28,30\% no teor de CLRt quando comparada com a fonte ARP (Figura 3B). A clorofila é um importante parâmetro de absorção de nitrogênio, pois a sua molécula apresenta quatro átomos de nitrogênio no núcleo central, onde ocorre a absorção de radiação solar (Taiz et al., 2017).

Aos 90 DAS, as fontes tiveram influência na quantidade de CRLt, em que a fonte ARS apresentou um valor de 49,84 ICF, sendo, 17,84\% superior ao observada na fonte ARP (Figura 3C). Estes resultados corroboram com o estudo realizado por Melo (2016), onde verificou-se maior índice de clorofilas em tratamentos que receberam a aplicação de água residuária de suinocultura. $\mathrm{O}$ teor de clorofila, por sua vez, geralmente, correlaciona-se positivamente com o teor de $\mathrm{N}$ foliar, devido a esse nutriente constituir parte de sua molécula (Carvalho et al., 2012). 
Figura 3. Desdobramento da interação diluição $x$ fontes de água residuária (piscicultura - ARP e suinocultura - ARS) para a clorofila total (CLRt) no milho aos 30 dias após a semeadura (DAS) (A e B) e, CLR $t$ no milho em função das fontes de água residuária aos 90 DAS (C).

A

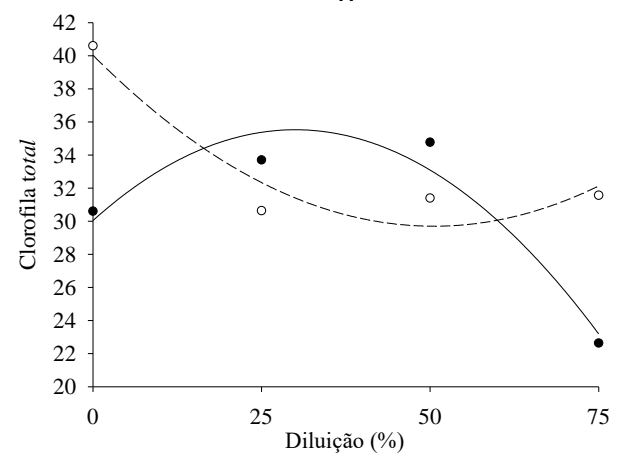

- $\quad$ ARP - CLR 30 DAS $=30,042+0,3657 * X-0,0061 * * \mathrm{X}^{2}-\mathrm{R}^{2}=0,9310$ - ARS - CLRt 30 DAS $=40,033-0,4093 * *+0,0041 * X^{2}-R^{2}=0,9038$

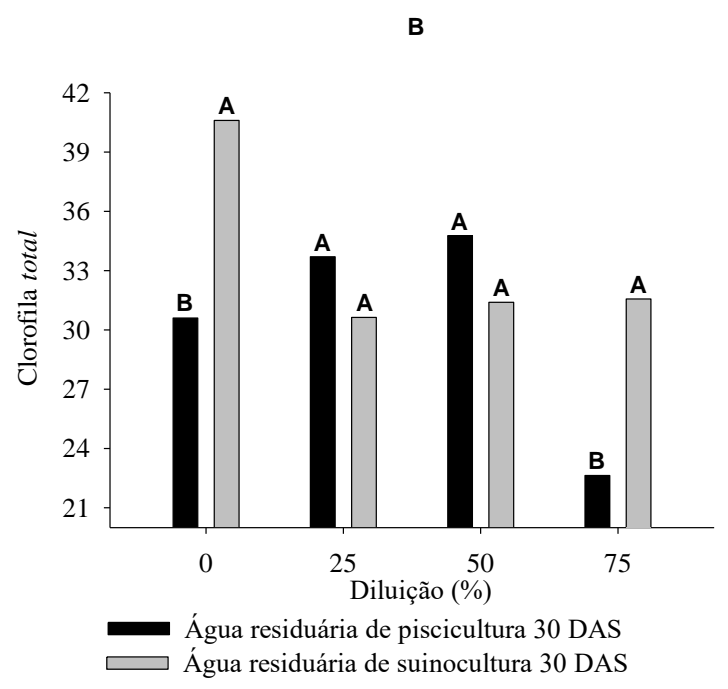

C

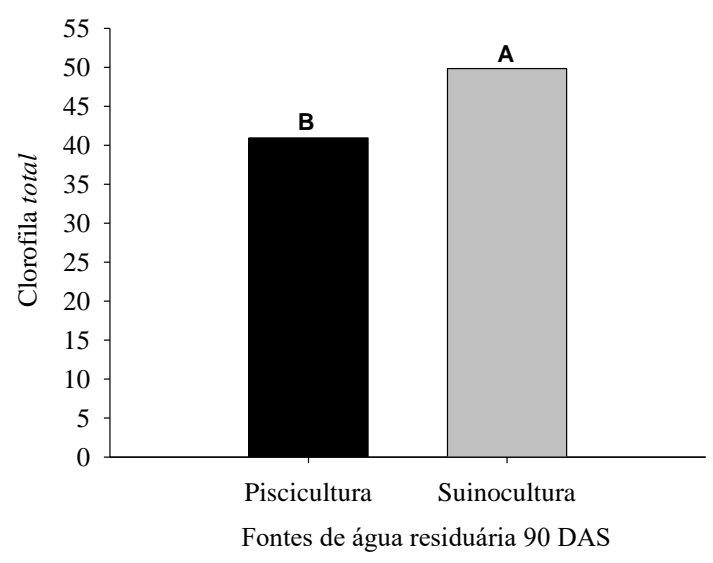

Fonte: Autores (2021).

Para a fonte ARP, os dados de índice SPAD aos 30 DAS não se adequaram aos modelos polinomiais de primeiro e segundo grau testados (Figura 4A). Na diluição de 51\% foi estimado o maior índice SPAD para a fonte ARS, igual a 35,88, sendo, a diluição de $0 \%$ a que proporcionou o menor índice $\operatorname{SPAD}(25,54)$.

Ocorreu diferença quando comparada as fontes utilizadas nas D de 25\%, 50\% e 75\% (Figura 4B), em que a fonte ARS proporcionou um aumento de 24,93, 21,56 e 29,18\%, respectivamente, no índice SPAD quando contrastada com a fonte ARP. 
Figura 4. Desdobramento da interação diluição $x$ fontes de água residuária (piscicultura - ARP e suinocultura - ARS) para a leitura SPAD na folha de milho aos 30 dias após a semeadura (DAS) (A e B) e leitura SPAD na folha de milho aos 60 (C) e 90 (D) DAS em função das fonres de água residuária.

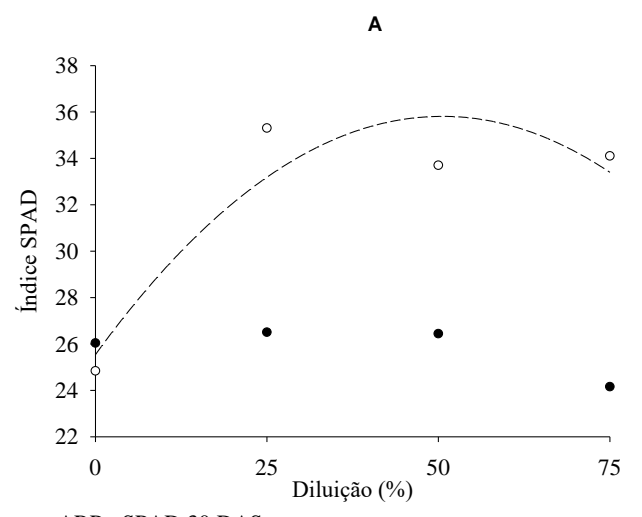

- $\quad$ ARP - SPAD 30 DAS

- ARS - SPAD 30 DAS $=25,537+0,4068 * * X-0,004 * X^{2}-R^{2}=0,8577$

C

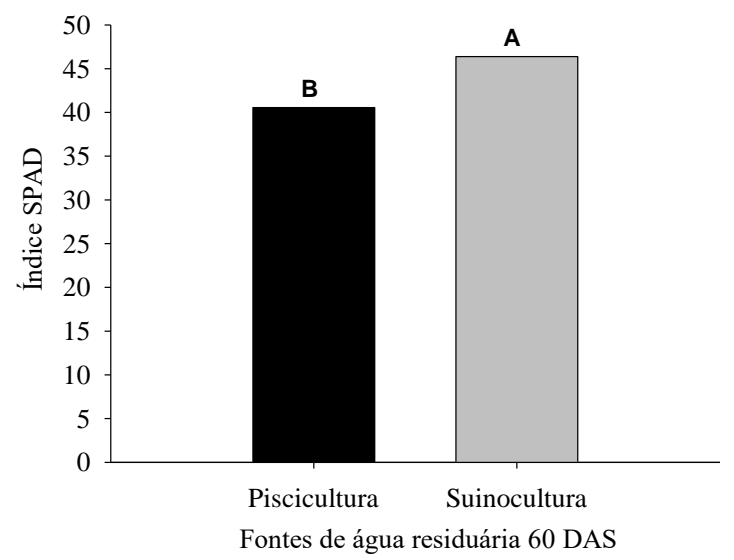

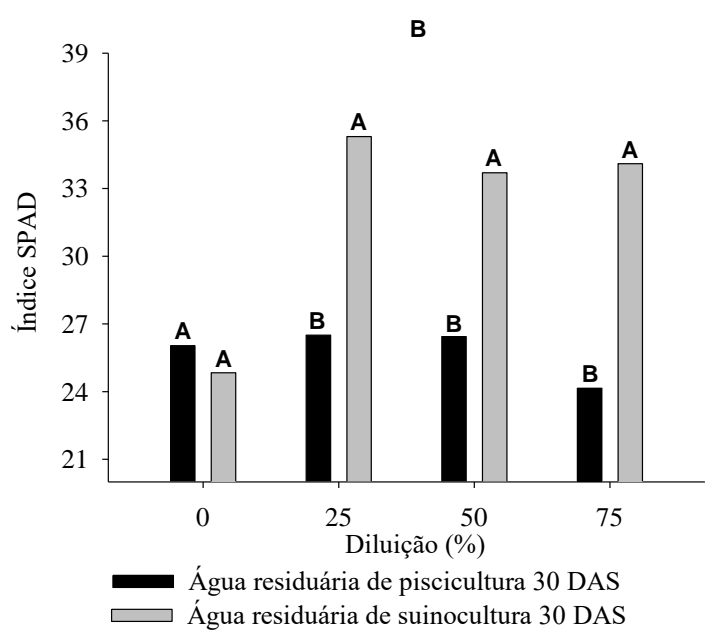

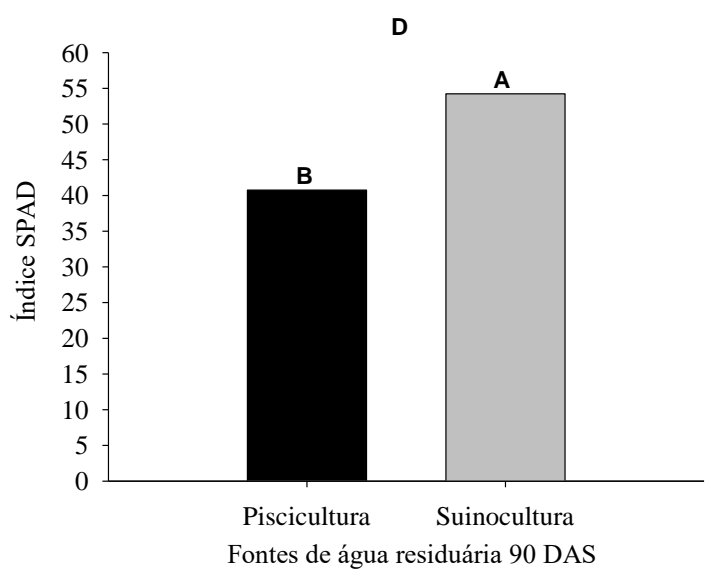

Fonte: Autores (2021).

Aos 60 e 90 DAS, as fontes exerceram influência no índice SPAD, em que a fonte ARS apresentou valor 12,55 e 24,85\%, respectivamente, superior ao índice SPAD observado na fonte ARP (Figura 4C e Figura 4D). Esse comportamento pode ser um reflexo do $\mathrm{N}$ mineral em cada fonte de água residuária, considerando que na ARS cerca de $93 \%$ do $\mathrm{N}$ total encontra-se na forma mineral, enquanto na ARP $73 \%$ do $\mathrm{N}$ já está mineralizado, reforçando os resultados obtidos por Ferreira et al. (2006) ao constatarem que os teores de clorofila mensurados pelo SPAD aumentam em plantas com maior disponibilidade de $\mathrm{N}$.

\section{Conclusão}

A fonte água residuária de suinocultura proporciona maior teor de clorofila $a$, clorofila $b$, clorofila total e leitura SPAD no final do ciclo do milho, independente da diluição utilizada.

Diluições acima de $75 \%$ reduzem a quantidade de clorofilas $a, b$ e total nas folhas de milho, em qualquer fase fenológica da planta. 


\section{Agradecimentos}

Os autores agradecem o Ministério da Ciência, Tecnologia, Inovações e Comunicações (MCTIC), à Fundação de Amparo à Pesquisa do Estado de Goiás (FAPEG), ao Conselho Nacional de Desenvolvimento Científico e Tecnológico (CNPq), à Coordenação de Aperfeiçoamento de Pessoal de Nível Superior (CAPES), à Financiadora de Estudos e Projetos (FINEP) e ao Instituto Federal Goiano (IF Goiano) pelo auxílio ao presente trabalho de pesquisa.

\section{Referências}

Bastos, R. K. (2016). Influência da água residuária da suinocultura sobre a acidez do óleo do pinhão manso (Jatropha curcas L.). Dissertação (Engenharia de Energia na Agricultura) - Universidade Estadual do Oeste do Paraná, Cascavel.

Cabral Filho, F. R. (2019). Desempenho agronômico e balanço nutricional na planta de milho fertirrigado com vinhaça concentrada e cloreto de potássio. Dissertação (Mestrado em Ciências Agrárias - Agronomia). Instituto Federal Goiano - Campus Rio Verde, Rio Verde - GO.

Carvalho, M. A. F., Silveira, P. M. \& Santos, A. B. (2012). Utilização do clorofilômetro para racionalização da adubação nitrogenada nas culturas do arroz e do feijoeiro. Santo Antônio de Goiás: Embrapa Arroz e Feijão.

Carvalho, N. L. \& Zabot, V. (2012). Nitrogênio: nutriente ou poluente? Revista Eletrônica em Gestão, Educação e Tecnologia Ambiental, 6 (6), 960-974.

Cassol, P. C., Costa, A. C., Ciprandi, O. \& Pandolfo, C. M. \& Ernani, P. R. (2012). Disponibilidade de macronutrientes e rendimento de milho em Latossolo fertilizado com dejeto suíno. Revista Brasileira de Ciência do Solo, 36 (6).

Coelho, A. M., França, G. D. (1995). Seja o Doutor do seu Milho. Arquivo do agrônomo n² Potafos.

Dutra, A. D. (2016). Adubação nitrogenada via fertirrigação em arroz irrigado por aspersão. Tese (Manejo e Conservação do solo). Universidade Federal de Pelotas, Pelotas.

Falker Automação Agrícola Ltda. (2008). Manual do medidor eletrônico de teor clorofla (ClorofLOG / CFL 1030). Falker, 33p.

Ferreira, D. F. (2011). Sisvar: a computer statistical analysis system. Ciência e Agrotecnologia, 35 (6), $1039-1042$.

Ferreira, M. M. M., Ferreira, G. B., Fontes, P. C. R. \& Dantas, J. P. (2006). Índice SPAD e teor de clorofila no limbo foliar do tomateiro em função de doses de nitrogênio e da adubação orgânica, em duas épocas de cultivo. Revista Ceres, 53 (305), 83-92.

Gonçalves, A. K. A., Silva, T. R. B. \& Brandão, A. G. (2016). Manejo de adubação nitrogenada em milho solteiro e em consorciado com brachiaria ruziziensis. Revista Brasileira de Milho e Sorgo, 15 (2), 318-327.

Instituto brasileiro de geografia e estatística - IBGE. (2018). Produção Agrícola - Lavoura Temporária. https://cidades.ibge.gov.br/brasil/go/rioverde/pesquisa/14/0?localidade1=52. Acesso em: 27 de novembro de 2019.

Köppen, W., Geiger, R. Klimate der Erde. Gotha: Verlag Justus Perthes. 1928. Wall-map 150cmx200cm.

Lopes, N. F. \& Lima, M. G. S. (2015). Fisiologia da produção,: Ed. UFV, 492 p.

Martins, C. A. C., Santos, F. S., Portz, A. \& Santos, A. M. (2018). Desenvolvimento inicial do milho (Zea Mays L.) em substrato contendo lodo de esgoto compostado. Revista Brasileira de Ciências Ambientais (Online), 48, 69-79.

Matos, A.T. \& Matos, M. P. (2017). Disposição de águas residuárias no solo e em sistemas alagados construídos. Editora UFV, 1, 371p.

Melo, D. (2016). Plantas de cobertura em áreas de produção de soja no verão e silagem de milho no inverno, com aplicação de água residuária de suinocultura. Tese (Engenharia Agrícola). Universidade Estadual do Oeste do Paraná - Campus Cascavel, Cascavel.

Melo, F. B., Corá, J. E. \& Cardoso, M. J. (2011). Fertilização nitrogenada, densidade de plantas e rendimento de milho cultivado no sistema plantio direto. Revista Ciência Agronômica, 42(1), 27-31.

Minolta. Camera Co. Ltd., Chlorophyll meter SPAD-502. Instruction manual. (1989). Osaka: Minolta Radiometric Instruments Divisions, 22p.

Moraes, M. T., Arnuti, F., Silva, V. R., Silva, R. F., Basso, C. J. \& Ros, C. O. (2014). Dejetos líquidos de suínos como alternativa a adubação mineral na cultura do milho. Semina: Ciências Agrárias, Londrina, 35(6), 2945-2954.

Moreira, R. C., Valadão, F. C. A. \& Júnior, D. D. V. (2019). Desempenho agronômico do milho em função da inoculação com Azospirillum brasilense e adubação nitrogenada. Revista de Ciências Agrárias Amazonian Journal of Agricultural and Environmental Sciences, 62.

Nascimento, T. S., Monteiro, R. N. F., Sales, M. A. L., Floriano, L. S. \& Pereira, A. I. A. (2016). Irrigação com efluente de piscicultura no cultivo de mudas de tomate. Revista Brasileira de Agricultura Irrigada, 10 (4), 866.

Neto, A. J. A., Lana, M. C., Rampim, L., Costa, L. A. M., Coppo, J. C. \& Alves, A. G. (2016). Água residuária de suinocultura sobre a produtividade de soja e milho segunda safra: uso e viabilidade econômica. Scientia Agraria Paranaensis, 15 (3), 350-357.

Neto, J. M. S. (2019). A produção de milho no sudoeste goiano: Espacialização, Cadeia Produtiva e Complementaridade. Dissertação (Geografia) Universidade Federal de Goiás, Goiânia. 
Research, Society and Development, v. 10, n. 7, e2510716251, 2021

(CC BY 4.0) | ISSN 2525-3409 | DOI: http://dx.doi.org/10.33448/rsd-v10i7.16251

Neto, T. I. O., Costa, M. C. G. \& Oliveira, V. P. V. (2016). Acúmulo de nitrogênio em plantas de milho crioulo em resposta à adubação orgânica. Revista Equador, 5 (4), 207-220.

Pereira A. S., Shitsuka, D. M., Perreira, F. J. \& Shitsuka, R. (2018). Metodologia da pesquisa científica. UFSM. Disponível em: https://repositorio.ufsm.br/bitstream/handle/1/15824/Lic_Computacao_Metodologia-Pesquisa-Cientifica.pdf?sequence=1.

Piekielek, W. P., Fox, R. H., Toth, J. D. \& Macneal, K. E. (1995). Use of a chlorophyll meter at the early dent stage of corn to evaluante N sufficiency. Agron. J., 87, 403-408

Santos, H. G., Jacomine P. K. T, Anjos, L. H. C., Oliveira, V. A., Lumbreras, J. F, Coelho, M. R, Almeida, J. A, Araujo Filho, J. C., Oliveira, J. B. \& Cunha, T. J. F. (2018). Sistema Brasileiro de Classificação de Solos. Brasília: Embrapa, (5a ed.).

Silva, F. C., Silva, M. M. \& Libadi, P. L. (2013). Aplicação de nitrogênio no cultivo de milho, sob sistema plantio direto: efeitos na qualidade física do solo e características agronômicas. Semina: Ciências Agrárias, 34 (6), 3513-3528.

Silva, P. F. (2018). Manejo da irrigação e da adubação nitrogenada no milho cultivado no outono/inverno em Botucatu-SP. Tese (Agronomia - Irrigação e Drenagem) - Universidade Estadual de São Paulo. Botucatu-SP.

Sousa, D. M. G. \& Lobato, E. (2004). Cerrado: Correção do solo e adubação. (2a ed.), Embrapa Informação Tecnológica, 416p.

Taiz, L., Zeiger, E., Moller, I. A. \& Murphy. A. (2017). Fisiologia e Desenvolvimento vegetal. (6a ed.), ArtMed.

Von Pinho, R. G., Borges, I. D., Pereira, J. L. D. A. R. \& Reis, M. C. D. (2009). Marcha de absorção de macronutrientes e acúmulo de matéria seca em milho. Revista Brasileira de Milho e Sorgo, 8 (2). 